\title{
Dreaming during lockdown: a quali-quantitative analysis of the Italian population dreams during the first COVID-19 pandemic wave
}

\author{
Lidia Borghi, ${ }^{1}$ Federica Bonazza, ${ }^{1}$ Giulia Lamiani, ${ }^{1}$ Alessandro Musetti, ${ }^{2}$ Tommaso Manari, ${ }^{2}$ Maria Filosa, ${ }^{3}$ \\ Maria C. Quattropani, ${ }^{4}$ Vittorio Lenzo, ${ }^{5}$ Maria Francesca Freda, ${ }^{6}$ Daniela Lemmo, ${ }^{6}$ Emanuela Saita, ${ }^{7}$ Roberto Cattivelli, ${ }^{7,8}$ \\ Gianluca Castelnuovo, ${ }^{7,8}$ Elena Vegni, ${ }^{1}$ Christian Franceschini ${ }^{3}$
}

${ }^{1}$ Psicologia Clinica, Dipartimento di Scienze della Salute, Università degli Studi di Milano, Milano; ${ }^{2}$ Dipartimento di Discipline Umanistiche, Sociali e delle Imprese culturali, Università di Parma, Parma; ${ }^{3}$ Dipartimento di Medicina e Chirurgia, Università di Parma, Parma; ${ }^{4}$ Dipartimento di Medicina Clinica e Sperimentale, Università di Messina, Messina; ${ }^{5}$ Dipartimento di Scienze della Società e della Formazione d'Area Mediterranea, Università per Stranieri 'Dante Alighieri' di Reggio Calabria; ${ }^{6}$ Dipartimento di Scienze Umanistiche, Università Federico II, Napoli; ${ }^{7}$ Dipartimento di Psicologia, Università Cattolica di Milano, Milano; ${ }^{8}$ Istituto Auxologico Italiano IRCCS, Laboratorio di Ricerca Psicologica, Milano, Italy

\begin{abstract}
Correspondence: Lidia Borghi, Psicologia Clinica, Dipartimento di Scienze della Salute, Università degli Studi di Milano, Via A. di Rudinì 8, 20142 Milano, Italy.

Tel.: +39.02.50323129. E-mail: lidia.borghi@unimi.it

Acknowledgements: we would like to thank all the people who participated in the study.
\end{abstract}

Contributions: $\mathrm{LB}$ and FB wrote the first draft of the study. CF, $\mathrm{AM}, \mathrm{LB}$ contributed in the design of the study; all the authors contributed in the data collection; LB, FB, and GL performed qualitative and quantitative analyses. All the authors critically revised the manuscript and approved the final version.

Conflict of interests: the authors declare no potential conflict of interests.

Availability of data and material: the data that support the findings of this study are available from the corresponding author [LB] on request.

Ethical approval and consent to participate: the study protocol was reviewed and approved by Ethics Committee of the Center for Research and Psychological Intervention (CERIP) of the University of Messina. Participants provided their written informed consent to participate in this study.

Consent for publication: participants gave consent for publication.

Citation: Borghi, L., Bonazza, F., Lamiani, G., Musetti, A., Manari, T., Filosa, M., Quattropani, M.C., Lenzo, V., Freda, M.F., Lemmo, D., Saita, E., Cattivelli, R., Castelnuovo, G., Vegni, E., \& Franceschini, C. (2021). Dreaming during lockdown: a quali-quantitative analysis of the Italian population dreams during the first COVID-19 pandemic wave. Research in Psychotherapy: Psychopathology, Process and Outcome, 24(2), 200-211. doi: 10.4081/ripppo. 2021.547

Received for publication: 3 April 2021.

Revision received: 13 July 2021.

Accepted for publication: 29 July 2021.

This work is licensed under a Creative Commons Attribution NonCommercial 4.0 License (CC BY-NC 4.0).

${ }^{\circ}$ Copyright: the Author(s), 2021

Licensee PAGEPress, Italy

Research in Psychotherapy:

Psychopathology, Process and Outcome 2021; 24:200-211

doi:10.4081/ripppo.2021.547

\begin{abstract}
This study aims to explore the emotional experiences related to the lockdown during the first pandemic wave, analysing the dreams of the Italian population. Through an online survey spread throughout the country, participants completed the Depression Anxiety Stress Scale-21 (DASS-21), the Resilience Scale (RS) and were asked to narrate a dream they had during the lockdown. The dreams were qualitatively analysed through the thematic content analysis. Logistic regression analyses were then conducted to verify the relationship among the categories that emerged and between these categories and the DASS-21 and RS scores. In the dreams 8 categories were identified (Places, Characters, Relationships, Actions, Danger, Death, Processes, and Emotions) composed of specific sub-categories, which seem to compose a sort of narrative structure of the dream. Some sub-categories were found to be predictor of depression and resilience or with exposure to COVID-19. Dreams can be a valid tool both to understand the experiences of the population during the pandemic and to evaluate those at risk of developing distress in clinical practice.
\end{abstract}

Key words: Dreams; COVID-19; mental health; distress; general population.

\section{Introduction}

The coronavirus disease 2019 (COVID-19) pandemic, which spread from December 2019, generated a global health emergency in a few months involving 223 countries (World Health Organisation [WHO], 2021), Italy being among the first. Due to the rapid spread and high rate of contagion, the Italian government attributed an emergency status to the situation, issuing a Decree of the President of the Council of Ministers (DPCM) on 9 March 2020, containing restrictive lockdown measures aimed at limiting the population being exposed to the virus and avoiding the collapse of the health system, forced to operate with insufficient knowledge and resources. Although the strict measures established effectively determined the slowdown of the epidemiological curve, at the same time they entailed a cost for the psy- 
chological well-being of the population (Pfefferbaum \& North, 2020).

Therefore, a growing interest emerged in international literature to explore mental health and psychological distress in the general population during the time of COVID19. Studies initially explored distress through the assessment of a priori chosen psychological dimensions collected in an agile, broad-based manner through selfadministered online surveys. As several literature reviews (Rajkumar, 2020; Salari et al., 2020; Vindegaard \& Benros, 2020) highlight, the main dimensions explored were anxiety, depression, post-traumatic stress, COVID-19 distress, and sleep disturbance. A high symptom prevalence in the general population was revealed on all dimensions. The same results were also found in studies conducted on the Italian population during the emergency phase of the first pandemic wave (Franceschini et al., 2020; Lenzo et al., 2020; Mazza et al., 2020; Rossi et al., 2020). As far as we know, to date there is a scarcity of qualitative studies exploring the emotional experience of the general population from an exploratory perspective starting from individual experiences. The qualitative studies performed were focused on the experience of specific subpopulations such as, for example, patients with COVID-19 (Sun et al., 2021) or healthcare workers (Liu et al., 2020).

In the context of population studies, some studies (Scarpelli et al., 2021; Gorgoni et al., 2020; Schredl \& Bulkeley, 2020; MacKay e DeCicco) explored the emotional experience of the general population through the investigation of dreams collected during the pandemic. People most at risk of infection and most affected by the pandemic and its lockdown (e.g., workers who have stopped working) were those who have reported higher emotional features (Schredl \& Bulkeley; Scarpelli et al., 2021). Considering changes in dream frequency, tone, and content as indicators of psychological distress may help identify individuals at greater risk for mental health problems.

Approaches and models that theorise the role and function of dreams and dream activity are varied and multifaceted. There is a genre of literature (Hartmann \& Basile, 2003; Davidson \& Lynch, 2012; Najam, Mansoor, Kanwal \& Naz, 2006) that highlights the importance of dream exploration during events with traumatic significance such as catastrophes and natural disasters, as they contain and reflect the collective emotional experience. Barrett (1996), in fact, asserts that dreams constitute a window on the trauma and its effects. One hypothesis postulates a continuity between dream activity and everyday events, in which therefore dream analysis can allow the comprehension of the experiences the population has had, and the sensitivity elicited by them (Fogli, Aiello \& Quercia, 2020). Moreover, an additional hypothesis to this one argues that dreams not only recover what is experienced in everyday life, but also constitute a mode of thought, albeit in a different state of consciousness, which allows the activation of processing and problem-solving processes (Barrett, 2017).

Through a qualitative-quantitative approach, this study aims to explore the contents and emotional experiences of the Italian population during the emergency phase of the first wave of the COVID-19 pandemic. In particular, the objectives are: i) to explore the presence of common contents in the dreams of individuals during the first lockdown period; ii) to explore whether a close exposure to COVID-19 (such us working in healthcare, living in Lombardy, having COVID-19, having a family member ill with COVID-19, and suffering a loss for COVID-19) influences the content of dreams; iii) to assess if psychological outcomes, such as resilience, stress symptoms, and anxiety or depressive symptoms, are predicted by dream contents.

\section{Materials and Methods}

\section{Study design}

This work is part of a larger multicentre research project, coordinated by the University of Parma, entitled 'Resilience during the time of COVID-19: how to react to perceived stress?'. The project was started in March 2020 during the first wave of the COVID-19 pandemic in Italy and aims to investigate, through a prospective design with a 6-month follow-up, the ways in which people cope with stress related to lockdown and the immediate and longterm effects on sleep quality, psychological distress, resilience, and dream activity (such as daydreaming and night dreaming) (for more details please refer Franceschini et al., 2020; Lenzo et al., 2020; Scarpelli et al., 2021; Musetti et al., 2021). The research project was conducted in accordance with the Declaration of Helsinki and the study protocol was approved by the Ethics Committee of the University of Messina. Each participant provided electronic informed consent.

Participation in the research project was on a voluntary basis. The research involved the completion of an online survey consisting of a sociodemographic section and a part of self-report questionnaires.

\section{Measurements}

\section{Socio-demographics}

Participants' sociodemographic data were collected (including gender, age, marital status, profession, considered in this study), data related to each individual's environmental reality (including, region in which they live), data related to COVID-19 disease (including COVID-19 infection, loved one affected by COVID-19 and having experienced a COVID-19 bereavement, considered in this study). The survey continued with the completion of several questionnaires including those in question in this work: i) the Depression Anxiety Stress Scale-21 (DASS- 
21) by Lovibond and Lovibond (1995); and ii) the Wagnild and Young Resilience Scale (RS) by Wagnild and Young (1993).

\section{Depression, anxiety and stress}

To screen for symptoms of anxiety, depression, and stress The Depression Anxiety Stress Scale-21 (DASS21) was used. Participants were asked to complete each item, rating the severity of depression ('I felt that I had nothing to look forward to'), anxiety ('I felt I was close to panic') and stress ('I found it hard to wind down'). The DASS-21 has 21 items, each item ranges from 0 ('did not apply to me at all') to 3 ('applied to me very much or most of the time'). The total score ranges from 0 to 46 , higher scores indicate more severe levels of depression, anxiety and/or stress.

\section{Resilience}

To assess resilience The Wagnild and Young Resilience Scale (RS) was used. RS is a 24-item self-report instrument, composed by five sub-scales: meaningfulness ('I seldom wonder what the point of it all is.'), self-reliance ('I can get through difficult times because I've experienced

difficulty before.'), perseverance ('Sometimes I make myself do things whether I want to or not'), existential aloneness ('I can be on my own if I have to.') and equanimity ('Keeping interested in things is important to me.'). Participants complete each item, expressing the degree of agreement with the statements with a score ranging from 1 (strongly disagree) to 7 (strongly agree). The total score ranges from 0 to 193 , higher scores indicate higher resilience.

\section{Dream}

To collect dreams, a blank section was left at the end of the questionnaire to freely write about a dream had during the lockdown period. The instructions were as follows: 'If you want, you can write in the space below about a dream you had during this lockdown period at home. Feel free to recount it as you see fit.'

\section{Data collection}

The survey was administered in 'self-report' and anonymous form through an identification code via an online platform (Microsoft Azure). The dissemination of the link related to the online completion of the survey took place through the universities' communication systems, online forums (e.g., through virtual learning environments, Facebook or WhatsApp accounts, etc.) or WeChat groups. Data collection began on 8 March 2020 (publication date of DPCM) and ended on 4 May 2020 (suspension date of the restrictive measures introduced by DPCM).

Of all the project respondents, the individuals who had recounted a dream and completed the DASS-21 and RS scales were included in this work.

\section{Data analysis}

The dreams were analysed by two researchers (LB and FB), who independently read and analysed them by using a dream content thematic analysis (Boyatzis, 1998). Thematic analysis is a process for qualitative coding of texts that identifies, analyses, and aggregates content patterns (themes) within the data (Braun \& Clarke, 2006). The analysis involved several distinct moments:

i) reading of the entire dream corpus by the two researchers and extrapolation from each dream of the emerging 'raw' categories or sub-categories. In this phase, starting from the dream text, they tried to identify the different sub-categories that described the different elements of the dream.

ii) grouping of the sub-categories into superordinate conceptual categories, with a higher level of abstraction, which would help to organise the elements of the dream. This step was accomplished through several meetings between the researchers. Any disagreements were resolved through a discussion with a third researcher involved (GL). This shared work led to the development of a coding grid (via Excel database) consisting of categories and sub-categories.

iii) application of the coding grid to the entire dream corpus, after an initial co-coding between researchers of $10 \%$ of the dreams. In this stage, the sub-categories were used as binary coding variables with respect to the presence $(0=$ no, $1=$ yes $)$ of the relevant content in each individual's dream. The subcategories were applied to dreams in a mutually exclusive manner.

iv) identification of dream extracts as exemplifications of the identified sub-categories.

This first stage of qualitative analysis led to the identification of the categories and their sub-categories, which were then analysed from a quantitative point of view, noting their frequencies. A subsequent step of quantitative analysis explored the relationship between these sub-categories and some outcome variables. Specifically, logistic regression analyses were performed to: i) assess the possible influence of dream sub-categories on the emotions of the dream; ii) assess whether the degree of exposure to COVID-19 (area of residence, health profession, COVID-19 positivity, COVID-19-related bereavements) predict the sub-categories of dreams; iii) assess whether the sub-categories of dreams predict psychological outcome variables (resilience, anxiety, depression, stress). These variables were transformed into dichotomous variables. Specifically, high resilience index scores $\geq 126.6$ at RS were considered in agreement with Girtler and colleagues (2010); moderate to severe anxiety, depression, and stress index scores (scores $\geq 10,14$, and 19 , respectively) were considered at DASS-21. 


\section{Participants}

Of 6439 individuals who participate at the larger multicentre research project, 761 (response rate: $11.8 \%$ ) wrote a dream and completed the DASS-21 and RS scales.

Table 1 describes the composition of the sample, including sociodemographic characteristics and COVID-19 data of the individuals involved. Participants were predominantly women $(\mathrm{n}=630 ; 82.8 \%)$, with an average age of $33(\mathrm{SD}=12.41)$. More than half of the sample $(\mathrm{n}=450$; $59 \%)$ lived in Northern Italy, with a third $(\mathrm{n}=264 ; 34.6 \%)$ residing in Lombardy.

\section{Results}

\section{Categories related to dream elements}

Figure 1 summarises and illustrates the categories and sub-categories that organise the elements of dreams.
The categories seem to be articulated as if to compose a sort of narrative structure of the dream, within which they assume a different and specific function. Two categories (Places and Characters) define the frame of the dream scene: Places indicate the dream setting, that is, where the dream scene takes place; Characters represent the parties of the dream in addition to the individual him/herself (not always present) and therefore indicate who is present in the dream. Four categories are purely thematic and are related to the 'unfolding' of the dream, or to 'what happens' in the dream, which may have to do with Relationality, with Actions or with situations of Danger or Death. The Processes category seems to indicate 'how' the dream situation is dealt with; finally, the Emotions in the dream category refers to the general experience of the dream. Not all categories are present in all dreams.

The categories and specific sub-categories will be described below, along with example excerpts from the individuals' dreams and their frequency relative to the entire dream corpus.

Table 1. Sample characteristics.

\begin{tabular}{|c|c|}
\hline Characteristics & $N=761$ \\
\hline $\begin{array}{l}\text { Gender, n (\%) } \\
\text { Women }\end{array}$ & $630(82.8)$ \\
\hline $\begin{array}{l}\text { Age } \\
\text { Mean (SD), range }\end{array}$ & 33 (12.4), 18-73 \\
\hline $\begin{array}{l}\text { Marital status, } \mathbf{n}(\mathbf{\%}) \\
\text { Single } \\
\text { Into a relationship } \\
\text { Married/cohabitee } \\
\text { Separated/divorced/widowed }\end{array}$ & $\begin{array}{l}261(34.3) \\
222(29.2) \\
251(33) \\
27(3.5)\end{array}$ \\
\hline $\begin{array}{l}\text { Area of residence, } \mathbf{n}(\%) \\
\text { Northern Italy } \\
\text { Central Italy } \\
\text { Southern Italy }\end{array}$ & $\begin{array}{l}450(59.1) \\
64(8.4) \\
247(32.5)\end{array}$ \\
\hline $\begin{array}{l}\text { Residence in Lombardy region, } \mathbf{n}(\mathbf{\%}) \\
\text { Yes } \\
\text { No }\end{array}$ & $\begin{array}{l}156(20.5) \\
605(79.5)\end{array}$ \\
\hline $\begin{array}{l}\text { Working in contact with the public, } \mathbf{n}(\mathbf{\%}) \\
\text { Yes } \\
\text { No }\end{array}$ & $\begin{array}{l}510(67) \\
251(33)\end{array}$ \\
\hline $\begin{array}{l}\text { Health profession, } \mathbf{n}(\mathbf{\%}) \\
\text { Yes } \\
\text { No }\end{array}$ & $\begin{array}{c}47(6.2) \\
714(93.8)\end{array}$ \\
\hline $\begin{array}{l}\text { COVID-19 positivity, } \mathbf{n}(\mathbf{\%}) \\
\text { Yes } \\
\text { No } \\
\text { Having symptoms, but no testing for COVID-19 } \\
\text { Other (e.g., 'I don't know') }\end{array}$ & $\begin{aligned} 10 & (1.3) \\
701 & (92.1) \\
34 & (4.5) \\
16 & (2.1)\end{aligned}$ \\
\hline $\begin{array}{l}\text { Having had a family member with COVID-19, } \\
\text { Yes } \\
\text { No }\end{array}$ & $\begin{array}{l}623(81.9) \\
138(18.1)\end{array}$ \\
\hline $\begin{array}{l}\text { COVID-19-related bereavements, n (\%) } \\
\text { Yes } \\
\text { No }\end{array}$ & $\begin{array}{c}51(6.7) \\
710(93.3)\end{array}$ \\
\hline
\end{tabular}




\section{Places}

The 'Places' category is divided into three sub-categories: i) Closed or labyrinthine places; ii) Familiar or known places; iii) Open places or places of escape. Places are present in $42 \%(n=379)$ of the dreams, which therefore have a specific spatial location. Among them, Closed or labyrinthine places recur in $43 \%(\mathrm{n}=161)$ of the dreams and define all closed environments ('at the bar', 'in a $c a r$ '), environments in which the individual feels restricted ('locked in a garage without a key to open the door.') or that have such a conformation that there is no way out ('...every now and then the supermarket turns into a labyrinth...', 'I was trying to climb the stairs, as if to go to the attic, but they were endless'). Familiar or known places, which characterise $35 \%(n=134)$ of the dreams, include places known and frequented in everyday life, such as one's own home and that of loved ones ('at a friend's house'), study ('...the branch of my university') and work environments. Lastly, the Open places or places of escape, recurred in $22 \%(n=84)$ of the dreams, are open spaces ('I was in a big square'), places far from one's everyday life or exotic places ('Like other times, I dreamt of going back to the Maldives...'), often with close contact with nature ('I was walking on the sand and the sea wet my bare feet...the beach was deserted and silent around me, on a bright, calm day. In front of me I could see the mountain that bordered this small gulf and I continued to walk with this relaxed feeling...').

\section{Characters}

The most recurring category is that related to Characters: $63 \%(n=463)$ of the analysed dreams, in fact, presented one or more people; specifically, $54 \%$ of these dreams ( $\mathrm{n}=396)$ involved a Known person, that is, a family member, a friend or a colleague, $13 \%(\mathrm{n}=95)$ an Unknown person ('a girl', 'a man'), 10\% ( $\mathrm{n}=74)$ an Enemy person ('a group of jihadists', 'a snake that wanted to bite $m e$ '), $10 \%(\mathrm{n}=77)$ a Deceased person ('a neighbour of mine who recently died', 'my grandmother who passed away last summer'), and $5 \%(\mathrm{n}=37)$ an Unborn person, such as new-borns or pregnant women ('my cousin's newborn son', 'a friend of mine who was pregnant').

\section{Relationality}

Relationality, which defines a relational episode or event occurring in the dream, is the second most frequent category, after Characters, and is present in $43 \%(n=319)$ of dreams. This category was extracted from three specific sub-categories: i) Relationality 'that unites'; ii) Relationality 'that divides'; iii) Dangerous relationality. The Re-

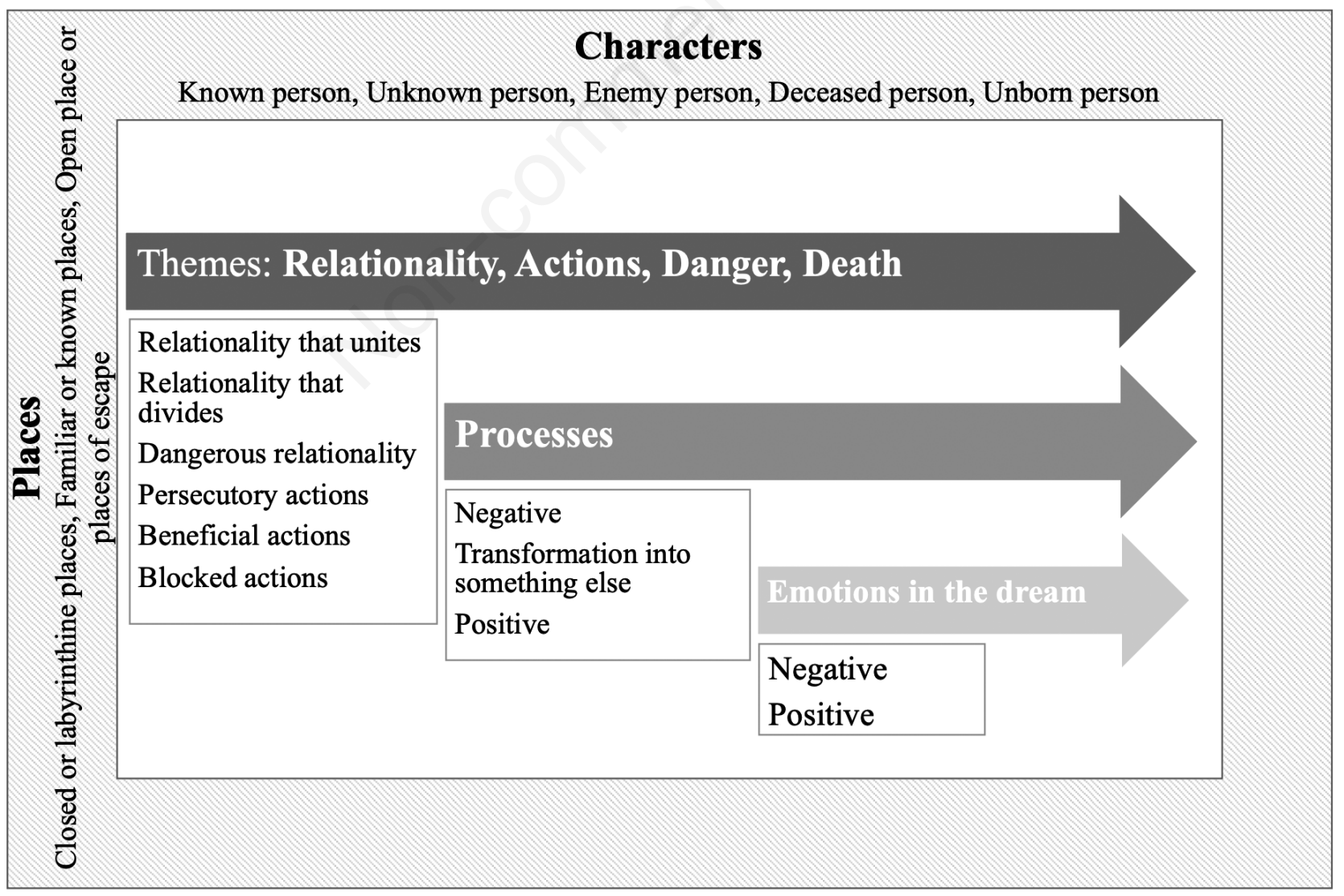

Figure 1. Categories related to dream elements. 
lationality that unites sub-category was identified in 31\% $(n=229)$ of the dreams and includes all dream content that has to do with the beginning of a new relationship ('I was engaged with a new guy', 'I dreamt of kissing the guy I'm in love with'), a situation of sharing and conviviality ('...I put decorations on the wall and organised a group video call with friends and relatives') or a reunion ('my son, who is abroad to study, returning home', 'a hug').

The Relationality that divides sub-category accounts for $13.4 \%(n=99)$ of the dreams and identifies dream content that has to do with relationships that go through a break-up, harmed by a betrayal committed ('I dreamt about betraying my partner even though I didn't want to') or suffered ('I dreamt that my husband loved another woman'), by quarrels and misunderstandings, or abandonment ('my boyfriend left me ... my mother left for an unknown destination'). Finally, the Dangerous relationality sub-category, present in $10 \%(\mathrm{n}=78)$ of the dreams, was attributed to dream content concerning situations in which interaction with the other person generates alertness and fear for one's own or others' safety ('I dreamt that I was going to the market and no one was wearing a mask, not even me ... I had to run away.'). This also includes crowded situations, where crowds hinder compliance with pandemic prevention rules, generating fear and alarm ('... a room full of people and fear of having been infected', '... a crazy crowd was on the other side of the fence').

\section{Actions}

The Actions category also refers to "what happens in the dream' but unlike Relationality, it includes all those actions carried out by the Characters and is present in $35.2 \%(\mathrm{n}=258)$ of the dreams. The Actions category is composed of 3 sub-categories, the first two with opposite polarity: i) Persecutory actions; ii) Beneficial actions; iii) Blocked actions. Each was then characterised by whether it was carried out by the dreaming individual ('active' action) or by another person often towards the dreaming individual ('passive' action).

The Persecutory actions sub-category includes all dream content describing actions that have the aim and/or effect of harming and causing physical or psychological pain. These actions are 'passive' in $26 \%(\mathrm{n}=192)$ of the dreams, whereby it is the dreaming individual who is attacked ('When I entered the lake I was attacked by many snakes and I felt the bites on my hands and them squeezing me around my hips. '), is insulted or mocked, is excluded ('I dreamt my room was occupied and there was no room for me'), is chased ('I was running home at night

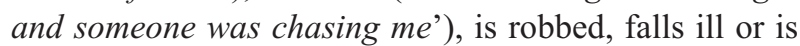
infected with the virus ('I was infected by an acquaintance...'). The sub-category also includes all dream content that describes persecutory actions actively carried out by the individual to the detriment of others. These occur in $8 \%(\mathrm{n}=60)$ of the dreams, where the subject actively injures, kills or tortures ('I kill a cat for fun', 'I had to cut some people's throats to defend myself'), offends, captures or imprisons ('I'm a poacher who captures animals to take them to the circus'), does not respect rules or norms (often virus-related) or infects others as a result of misbehaviour ('...One day I began to realise that I had become a 'criminal'because I had somehow done something illegal in relation to the tyrannical rules of the moment").

The Beneficial actions sub-category included all dream content that indicates actions in which one performs (active) or is the recipient (passive) of an action which benefits oneself and others. Passive Beneficial actions characterise $4 \%(n=30)$ of the dreams and identify those challenging situations, in which the individual receives the decisive intervention of others, for which he is rescued or saved ('I dreamt of wanting to jump off a bridge under which the water was dark and dirty but a dolphin, jumping several times out of the water, prevented me from doing so, it actually made me happy'), consoled ('my deceased grandfather who told me that this bad period would pass') or helped ('I try to climb up and over the wall in front of me and I always find someone who helps me', 'I came up with a plan with the help of a strange animal that also helped me to carry it out'). Active Beneficial actions are present in $9 \%(\mathrm{n}=71)$ of the dreams and identify dream content in which the same actions are actively carried out by the individual, who saves ('There was a great feast, a banquet. They brought a roast lamb, but I realised that the lamb was still alive. I started shouting in the mad crowd to save that poor lamb'), helps ('I dreamt of helping a stranger after an accident, after having called 118'), runs away to save him/herself, complies with and enforces the preventive rules for the spread of the virus ('I dreamt I was in a church with lots of people... I was really trying hard, at least, to keep people as far apart from each other as possible').

The Blocked actions sub-category recurs in $24 \%$ $(n=184)$ of the dreams and includes all dream content in which an action does not materialise because the intentions of the dreaming individual and/or of the other people are inhibited by other intervening people ('I dreamt of going out with friends and we were organising an evening, but someone would always come and say 'oh no, we can't') or by limiting circumstances ('I had to play chess with some very heavy elephants that I found difficult to move', 'I had lots of cats and, trying to put them all in one room, I realised I couldn't do it because they were trying to escape.') or situations of blockage or helplessness ('I can't react and I remain motionless, staring at the sea that wants to swallow me, and I let it, I have a feeling of anguish').

\section{Danger}

The Danger category, present in $23 \%(\mathrm{n}=160)$ of the dreams, concerns dream content in which a state of alertness or a fear of danger emerges, in which the dreaming individual and/or the people involved fear for their own or others' safety. It differs from the Dangerous relationality 
sub-category because the danger does not concern a relational situation; it differs from the Persecutory actions subcategory because it does not concern an action suffered but a situation of danger or fear of danger. This category includes dream content that concerns environmental disasters ('I' $m$ in a boat with lots of friends in the middle of a storm ...', 'a tsunami', 'the sand starts spinning around me and the grains of sand turn into letters and like a vortex, the sand/letters squeeze me tight'), or situations of danger or fear ('I was afraid of falling'; 'afraid that the buildings would collapse'; 'I was afraid I had lost one of my children and I was distressed'), of getting sick/being ill, for example ('they called me because my dad wasn't breathing, he was sitting on the ground in a concrete car park').

\section{Death}

The Death category, which occurs in $9 \%(n=66)$ of the dreams, concludes 'what happens' by grouping together all the dream content that refers to situations in which the dreaming individual faces his/her own death ('I dreamt I was in my grandmother's house in the fields, I was looking around as if I were a ghost, nobody could see me ... My body was lying on the ground with a blood soaked jute sack on my head (I think I had shot myself in the head)'), witnesses that of his/her loved ones ('I dreamt my husband died when a building collapsed') or of people involved in the dream ('I was going to do the shopping with my brother, we went in in the morning but by the time we managed to get out it was evening. Instead of going to the basement to get the car, lost in thought, I pressed button 3 of the lift. The doors opened and a sort of field hospital had been set up. There were a lot of hospital beds with dead people in them. Only one boy was alive, he was coming towards me and in the midst of all that death he just wanted a hug, some human contact. I ran away out of fear'). This category does not include contents that refer to the deceased (included in the corresponding Characters category) or to situations where there is a danger of death (Danger) or a persecutory threat of death (passive Persecutory actions).

\section{Processes}

The Processes category is present in $31 \%(n=223)$ of the analysed dreams and refers precisely to dream content that testifies to how dream events are faced, resolved or concluded, thus including those mechanisms which are posed in the dream, influencing the outcome of the dream events. The Processes category is composed of three subcategories, the first two with opposite polarity: i) Positive processes; ii) Negative processes; iii) Transformation processes into something else.

The Positive processes, present in $7 \%(n=53)$ of the dreams, include all dream content that indicates events or mechanisms of repair or resolution ('the boy who left me for no reason comes back to me and regrets it'; 'the thief who stole my car gives it back to me and, as an apology, delivers the shopping to my door'; 'the door was falling to pieces, the plaster was peeling off, but I wasn't distressed by all of this, I calmly tidied up and watched with curiosity as the walls revealed themselves and the unnoticed corners appeared') or of renewal or rebirth ('there was a lot of icy snow covering the grass, but then it would melt') relating to the events of the dream.

The Negative processes, on the other hand, describe $21 \%(n=159)$ of the dreams and include all dream content that refers to mechanisms of destruction or collapse (' $I$ dreamt of my husband's death when a building collapsed'), fading or loss of form ('I was walking along a path with a girl behind me and this path turned into some steep rocky passages, I carried on carefully, the handholds were crumbly') or which concern disappearing, losing oneself ('I lose my bearings because of the size of the house') or transformation into the opposite (often positive conditions into negative), which also includes situations characterised by emotional ambivalence or oscillation between opposite emotions ('the beautiful place gave me great joy, but sadness/anguish/loneliness strongly prevailed and I felt the pain even more...').

Transformation processes into something else, present in $10 \%(n=77)$ of the dreams, include all dream content that concerns processes of form transmutation (' $I$ dreamt I saw things falling from the sky which looked like snow. Looking at them more closely I realised they were bird feathers', 'the chandelier becomes a coloured lampshade hanging by a really long cord that starts to descend on the bed.... Looking more closely at that spot, I can see that patches of mould have formed and from these patches that are increasingly numerous and closer together, all these little black larvae start to emerge, larvae that immediately turn into bees.') or acquiring different appearances or powers ('I was a guy playing at a concert ... When the concert was over, I turned into a wolf ...', 'I dreamt I had paranormal powers ...').

\section{Emotions in the dream}

The Emotions in the dream category includes dream content that refers to the emotional experience of the dream. It is composed of two sub-categories: i) Positive emotions; ii) Negative emotions. The Positive emotions sub-category, present in $17 \%(n=126)$ of the dreams, was attributed to dream content that explicitly expresses positive experiences, which include feelings of joy, happiness, niceness, satisfaction, tranquillity, serenity and peace. For example, 'I have to hold a conference however I'm unprepared, but I'm not worried, I'm eating a sandwich with colleagues, I'm happy that two colleagues with whom I had romantic relationships - are talking to each other again'or 'I'm in the Maldives and I'm happy'.

The Negative emotions sub-category is present in $55 \%(n=416)$ of the dreams and was attributed to dream content that explicitly expresses negative experiences, 
which include feelings of sadness, pain, suffering, anger, dissatisfaction, helplessness, confusion, anxiety, fear, panic, disgust, contempt, shame and guilt. For example, 'I dreamt that I was with my boyfriend on a train, and I felt uncomfortable. At one point he disappears, and some guys come up and rape me' or 'Half of the desperate and still human crowd were running like me towards the cars, trying not to be grabbed and defending themselves with whatever they could, intent on stabbing these creatures that were attacking us...... I defended myself and knocked the creature down ... after stabbing it unsuccessfully in the belly, stomach, throat and neck, in tears I moved on to the eye sockets, and stabbed again and again until it stopped moving. I woke up due to the agitation'.

In $29 \%$ ( $n=219)$ of the dreams it was not possible to attribute the Emotions in the dream category, either because no emotion was explicit or because it was neutral, uncertain or not clearly defined and recognisable (e.g., ' $I$ was before a sacred image. Christ on the cross. I approached to kiss his feet and this Christ became a strange being who told me 'I am not for You').

\section{Influence of the sub-categories of the dream on the Emotions}

In the light of the qualitative analysis performed, we decided to conduct regression analyses to assess the possible role of the sub-categories in predicting Emotions of the dream.

Table 2 shows the results of the logistic regression, where the Emotions in the dream category was included as a dependent variable (where $0=$ negative emotions and $1=$ positive emotions). The model was highly significant $\left(\mathrm{R}^{2}=0.68\right.$; Chi-square $\left.=225.5 ; \mathrm{P}<0.001\right)$. Positive emotions were predicted by the presence in dreams of Open places or places of escape, Relationality that unites and Positive processes. On the other hand, negative emotions were predicted by Relationality that divides, Persecutory actions (both active and passive), Blocked actions, Danger, Death, Negative Processes and Processes of transformation.

\section{Influence of exposure to COVID-19 on the sub-categories of the dream}

Analyses were performed to assess whether the subcategories of the dream were predicted by the degree of

Table 2. Associations between sub-categories of the dream and Emotions in the dream.

\begin{tabular}{|c|c|c|c|}
\hline Sub-categories of the dream included as covariates in the model* & $\begin{array}{l}\text { Odd ratio } \\
\text { (O.R.) }\end{array}$ & $\begin{array}{c}\text { Confidence interval odd ratio } \\
\text { (I.C. O.R.) }\end{array}$ & $\mathbf{P}$ \\
\hline Closed or labyrinthine places & 1.71 & $0.56-5.16$ & 0.343 \\
\hline Familiar or known places & 1.33 & $0.44-4.03$ & 0.614 \\
\hline Open places or places of escape & 5.72 & $2.07-15.77$ & 0.001 \\
\hline Enemy person & 2.10 & $0.30-14.62$ & 0.452 \\
\hline Unknown person & 2.79 & $0.89-8.77$ & 0.078 \\
\hline Known person & 0.81 & $0.31-2.14$ & 0.675 \\
\hline Deceased person & 0.89 & $0.25-3.20$ & 0.861 \\
\hline Unborn person & 2.82 & $0.30-26.28$ & 0.361 \\
\hline Relationality 'that unites' & 4.05 & $1.68-9.78$ & 0.002 \\
\hline Relationality 'that divides' & 0.04 & $0.01-0.32$ & 0.002 \\
\hline Dangerous relationality & 0.64 & $0.11-3.62$ & 0.614 \\
\hline Active Persecutory actions & 0.04 & $0.00-0.40$ & 0.007 \\
\hline Passive Persecutory actions & 0.04 & $0.01-0.21$ & 0.001 \\
\hline Active Beneficial actions & 2.33 & $0.52-10.44$ & 0.270 \\
\hline Passive Beneficial actions & 3.23 & $0.58-18.01$ & 0.182 \\
\hline Blocked actions & 0.05 & $0.02-0.17$ & 0.001 \\
\hline Danger & 0.08 & $0.02-0.36$ & 0.001 \\
\hline Death & 0.09 & $0.01-0.87$ & 0.037 \\
\hline Negative processes & 0.11 & $0.04-0.34$ & 0.001 \\
\hline Positive processes & 4.64 & $1.21-17.80$ & 0.025 \\
\hline Transformation processes into something else & 0.20 & $0.05-0.79$ & 0.022 \\
\hline
\end{tabular}

*The category Emotions in the dream was included as a dependent variable (with $0=$ Negative emotions and 1=Positive emotions). 
exposure to COVID-19 (the analysis was not conducted for 'COVID-19 positivity' due to too low a number). The only significant model $\left(\mathrm{R}^{2}=0.21\right.$; Chi-square $=35.1$; $\mathrm{P}=0.038$ ) was the one for the 'working in health care' variable, which predict a higher frequency of Unborn person (O.R. $=5.6, \mathrm{P}=0.023)$. The other models for living in the Lombardy region, having had a family member with COVID-19 or having experienced a bereavement for COVID-19 were not significant. Nevertheless, having had a family member with COVID-19 predict some sub-categories of dream content, and in particular: the presence of Unborn person (O.R. $=3.5, \mathrm{P}=0.015)$, Death $(\mathrm{O} . \mathrm{R} .=2.8$, $\mathrm{P}=0.004)$ and Transformation processes into something else (O.R. $=2, \mathrm{P}=0.044)$.

\section{Influence of the sub-categories of the dream on psychological outcomes}

Ultimately, analyses were performed to assess whether the sub-categories were distributed differently according to the psychological outcome variables. Although no model reached statistical significance, psychological outcomes were found to be predicted by some sub-categories of the dream. In particular, high resilience scores were predicted by the presence of Positive processes $(\mathrm{O} . \mathrm{R} .=2.6, \mathrm{P}=0.025)$. Negative emotions predict moderate to severe stress (O.R. $=0.7, \mathrm{P}=0.028$ ). A moderate to severe anxious symptomatology was predicted by the presence of Deceased people $(\mathrm{O} . \mathrm{R} .=2.3, \mathrm{P}=0.038)$ and to the absence of Positive processes $(\mathrm{O} . \mathrm{R} .=0.4, \mathrm{P}=0.032)$. Finally, the presence of Closed or labyrinthine places (O.R. $=1.6, \mathrm{P}=0.042)$, the absence of Active Beneficial actions (O.R. $=0.5, \mathrm{P}=0.028)$ and Negative emotions $(\mathrm{O} . \mathrm{R} .=0.7, \mathrm{P}=0.010)$ predict moderate to severe depressive symptoms.

\section{Discussion}

This study qualitatively and quantitatively explored the contents of the Italian population's dreams during the lockdown implemented in the first wave of the COVID19 pandemic. Dreaming is a psychic activity that takes place during sleep, meaning in a non-vigilant state of consciousness, characterised by emotions, perceptions and thoughts that are structured in a succession of images. Several theories have conceptualised dreaming as the fulfilment of an unconscious desire, the expression of needs, the continuation of psychic activities present in the waking state, or processing and problem solving. Our results seem to confirm the hypothesis that dreams can both be indicators of emotional experience and have a processing function.

In this regard, this study highlights how the settings of the population's dreams during lockdown reflect the condition experienced, and in fact the majority take place in closed, labyrinthine or claustrophobic places, with no way out. However, it should also be emphasised that in about a fifth of the dreams the setting is an Open place or place of escape, thus probably testifying to the experience of 'captivity' and an emotional need for openness. Moreover, the data seems to show how the plot of the dream events ('what happens') can trace the experiences and needs of the population. The most frequent category appears to be that of Relationality, which we can assume indicates the need for relational contacts but also fears of break-ups or the aspect of danger coming from relational contact, a typical aspect of COVID-19 disease. Moreover, the Blocked actions sub-category is present in a quarter of the dreams that include all the situations in which the behavioural intention of the individual or of the Characters is inhibited by environmental circumstances or by other parties intervening in the event and is often associated with afinalism and feelings of helplessness, which we can assume refer to the many experiences people have had to deal with as a result of the restrictive lockdown measures. Similarly, also the suffered Persecutory actions sub-category recurs in more than a quarter of the dreams analysed, and we may hypothesise that it refers to emotional experiences of 'persecution' due both to the pandemic situation and to the restrictive regulations but also to the profound situation of uncertainty. Specific themes also emerge (Danger and Death) that seem to refer to emotional experiences of alarm, danger and anguish, relating also to deadly and precarious aspects, aspects with which the lack of knowledge and the unpredictability of the COVID-19 disease confronted us, especially during the first pandemic phases. Finally, the dream content included in the Processes category appear to be of great relevance which, by understanding the mechanisms by which one deals with dream events, seem to reflect coping, problem solving or emotional processing processes.

The data analysis revealed the explicit presence of the Emotions in the dream category, which includes the positive or negative emotional tone of the dream. More than half the dreams analysed reported negative emotions, such as anxiety and panic, sadness, pain, helplessness or confusion. This result is in line with other studies (Schredl \& Bulkeley, 2020; MacKay \& DeCicco, 2020; Mota et al., 2020; Scarpelli et al., 2021), which, by collecting and analysing the dreams of the general population during the pandemic period, have observed a change in dream activity, with a higher frequency of dream content with negative significance compared to normal. Nevertheless, our analysis revealed a relationship between Emotions in dreams and the other dream sub-categories. Negative emotions are predicted by Relationality that divides, Persecutory actions (both active and passive), Blocked actions, Danger, Death, Negative processes and Transformation processes. This data therefore suggests that dreams with negative significance are linked with relational break-ups, danger or the deadly aspects of the pandemic and to the disease, but also to the feeling of being persecuted or blocked and helpless. In addition, 
dreams with a negative significance seem to be characterized by difficulties in coping or processing; in fact, destructive mechanisms or negative transformation prevail. Our data would therefore seem to suggest that dreams with a negative emotional experience reflect the psychological suffering experienced by the Italian population and the pandemic situation faced. At the same time, Positive emotions are predicted by Open places or places of escape, Relationality that unites and Positive processes. We can hypothesise that these dreams testify to the population's need for escape and contact during lockdown, but also a capacity for processing and transforming the situation in a sense of renewal or rebirth.

Our results also show how certain dream subcategories predict different psychological outcomes. Our results particularly indicate that negative dream emotions predict moderate to severe stress and depressive symptoms. The presence of Closed or labyrinthine places (and therefore probably claustrophobic feelings) predict moderate/severe depressive symptoms, while the presence of active Beneficial actions appears to be inversely associated with depressive symptoms. This data is in line with what emerged from a longitudinal study by Pesant and Zadra (2005), who demonstrated that psychological wellbeing is inversely correlated with dream content characterised by aggressive interactions, negative emotions and episodes of failure. In fact, according to the perspective that regards dream material as a continuity with daytime material, the content of dreams reflects what is experienced in everyday life (Domhoff, 1996; Domhoff, 2003; Fogli et al., 2020).

Our data also showed a relationship between the presence of Positive processes (i.e., renewal, repair and rebirth) in the dream and higher resilience scores. The presence of positive processes in dream content also appears to be inversely correlated with anxiety symptoms. This result is confirmed in the literature, since a hypothesis, now widely accepted and complementary to the continuity hypothesis, maintains that the dream is a time when thought continues, albeit in a different state of consciousness, leading, through the development of problemsolving strategies, to solutions to problems faced in everyday life (Barrett, 2017). From this point of view, dream activity probably allowed the population to recover and re-process the emotions and experiences encountered during the pandemic reality, then identifying the most effective strategies to respond adaptively to the stress of the pandemic reality (Fogli et al., 2020).

Our study seems to highlight a transversality of the contents and emotional experiences that emerged from the dreams, regardless of the greater or lesser degree of exposure to COVID-19, as if to indicate the universality of the emotional experiences encountered during the emergency phase of the first pandemic wave. Among the categories of individuals mostly exposed to the COVID-19 pandemic, our data revealed that health professionals and those who had a family member affected by COVID-19 reported Unborn people more frequently. One hypothesis is that these categories experience the potentially traumatic aspect of the pandemic as something that breaks the continuity of their experience and requires 'readjustment'. In this sense, the presence of unborn people could testify to a need or possibility for rebirth and renewal. In those who have had a family member affected by COVID-19, in addition to the same renewal experience, there are contents linked to the theme of death and transformative processes. Specific dream content, in fact, can characterise the dreams of a subgroup, becoming a manifestation of their implicit experience (Schredl \& Engelhardt, 2001).

This data is partially in line with the study of Schredl $\&$ Bulkeley (2020), which reported that the dreams most influenced by the pandemic situation are those of individuals whose lives are directly affected by the pandemic, either because of contagion or because of side effects in the psychosocial area (e.g., job loss).

In the light of the results obtained, it could be hypothesised that dreams could be a valid tool both for understanding the collective experiences of the general population during epochal events such as the COVID-19 pandemic, and in clinical practice for assessing the most vulnerable individuals or those at risk of developing distress.

From a clinical perspective, dream narration can also be an opportunity to identify individuals' needs and bring out memories, concepts and emotions, which might otherwise remain silent (Cartwright, 2011; Goelitz, 2001). At the same time, it can be a useful tool for identifying individuals who are exposed to conditions of greater distress or vulnerability. Indeed, dream content with negative emotional significance, especially those with a substantial experience of distress and anxiety, could be the outcome of maladaptive emotional functioning in everyday life (Levine \& Fireman, 2001), which can generate a condition of psychological suffering.

This study explored the content of the Italian population's dreams by adopting a qualitative-quantitative approach that looks at the dream phenomenon as an expression of collective experiences. A possible limitation lies in not asking each participant to make a subjective assessment of the emotional experience of the dream for example, and emotions were attributed starting from the content of the dream narration. Moreover, this approach does not allow for an individual assessment that correlates dream content with psychological outcomes, an assessment that is essential in clinical practice. Finally, our study involved mainly women, which is crucial to consider when reading and interpreting the data. Future studies should investigate the possible influence of gender on dream content.

A possible development of this work could explore the population's dream content in different phases of the pandemic period (e.g., the third wave or the post-pandemic period), in order to observe whether and how these dif- 
ferent realities have an effect on the population's dream activity. In addition, further studies could consider subpopulations, such as health care workers or patients with COVID-19 and hospitalised, with the aim of observing the possible presence of specific dream content or emotional experiences and their associations with psychological outcomes such as posttraumatic stress disorder.

\section{Conclusions}

This contribution helps in exploring the contents and emotional experiences of the Italian population during the emergency phase of the first wave of the COVID-19 pandemic. The findings highlighted a transversality of the contents and emotional experiences that emerged from the dreams, as if to indicate the effect of the pandemic on the entire population, including those not directly affected by COVID-19. Dreams can be a valid tool both to understand the experiences of challenging events and to evaluate those at risk of developing distress in clinical practice.

\section{References}

Barrett, D. (2001). Trauma and dreams. Harvard: Harvard University Press.

Barrett, D. (2017). Dreams and creative problem-solving. Annals of the New York Academy of Sciences, 1406(1), 64-67. doi: 10.1111/nyas.13412.

Boyatzis, R. E. (1998). Transforming qualitative information: Thematic analysis and code development. Newcastle upon Tyme: Sage.

Braun, V., \& Clarke, V. (2006). Using thematic analysis in psychology. Qualitative Research in Psychology, 3(2), 77-101. doi: 10.1191/1478088706qp063oa.

Cartwright, R. D. (2010). The twenty-four hour mind: The role of sleep and dreaming in our emotional lives. Oxford: Oxford University Press.

Davidson, J., \& Lynch, S. (2012). Thematic, literal and associative dream imagery following a high-impact event. Dreaming, 22(1), 58-69. doi: 10.1037/a0026273.

Domhoff, G. W. (1996). Finding meaning in dreams: A quantitative approach. Berlin: Springer.

Domhoff, G. W. (2003). The scientific study of dreams: Neural networks, cognitive development, and content analysis. American Psychological Association.

Franceschini, C., Musetti, A., Zenesini, C., Palagini, L., Pelosi, A., Quattropani, M. C., Lenzo, V., Freda, M. F., Lemmo, D., Vegni, E., Borghi, L., Saita, E., Cattivelli, R., De Gennaro, L., Plazzi, G., Riemann, D., Castelnuovo, G. (2020). Poor quality of sleep and its consequences on mental health during COVID-19 lockdown in Italy. Frontiers in Psychology, 11, 1-16. doi: 10.3389/fpsyg.2020.574475.

Fogli, A., Maria Aiello, L., \& Quercia, D. (2020). Our dreams, our selves: automatic analysis of dream reports. Royal Society Open Science, 7(8), 1-19. doi: 10.1098/rsos.192080.

Gazzetta ufficiale (2021). Decreto del Presidente del Consiglio dei Ministri 8 marzo 2020. ( $8^{\text {th }}$ March). Available from: https://www.gazzettaufficiale.it/eli/id/2020/03/08/20A01522/sg

Girtler, N. C. E. F., Casari, E. F., Brugnolo, A., Cutolo, M.,
Dessi, B., Guasco, S., Olmi, C., \& De Carli, F. (2010). Italian validation of the Wagnild and Young Resilience Scale: a perspective to rheumatic diseases. Clinical \& Experimental Rheumatology, 28(5), 669-78.

Goelitz, A. (2001). Nurturing life with dreams: Therapeutic dream work with cancer patients. Clinical Social Work Journal, 29(4), 375-385. doi: 10.1023/A:1012219314370.

Gorgoni, M., Scarpelli, S., Alfonsi, V., Annarumma, L., Cordone, S., Stravolo, S., \& De Gennaro, L. (2021). Pandemic Dreams: quantitative and qualitative features of the oneiric activity during the lockdown due to COVID-19 in Italy. Sleep medicine, 81, 20-32. doi: 10.1016/j.sleep.2021.02.006.

Hartmann, E., \& Basile, R. (2003). Dream imagery becomes more intense after 9/11/01. Dreaming, 13(2), 61-66. doi: 10.1023/A:1023398924124.

Lenzo, V., Quattropani, M. C., Musetti, A., Zenesini, C., Freda, M. F., Lemmo, D., Vegni, E., Borghi, L., Plazzi, G., Castelnuovo, G., Cattivelli, R., Saita, E., \& Franceschini, C. (2020). Resilience contributes to low emotional impact of the COVID-19 outbreak among the general population in Italy. Frontiers in Psychology, 11, 1-12. doi: 10.3389/ fpsyg.2020.576485.

Levin, R., \& Fireman, G. (2002). Nightmare prevalence, nightmare distress, and self-reported psychological disturbance. Sleep, 25(2), 205-212. doi: 10.1093/sleep/25.2.205.

Liu, Q., Luo, D., Haase, J. E., Guo, Q., Wang, X. Q., Liu, S., Xia, L, Liu, Z., Yang, J., \& Yang, B. X. (2020). The experiences of health-care providers during the COVID-19 crisis in China: a qualitative study. The Lancet Global Health, 8(6), 790-798. doi: 10.1016/S2214-109X(20)30204-7.

Lovibond, P. F., \& Lovibond, S. H. (1995). The structure of negative emotional states: Comparison of the Depression Anxiety Stress Scales (DASS) with the Beck Depression and Anxiety Inventories. Behaviour research and therapy, 33(3), 335-343. doi: 10.1016/0005-7967(94)00075-u.

Mazza, C., Ricci, E., Biondi, S., Colasanti, M., Ferracuti, S., Napoli, C., \& Roma, P. (2020). A nationwide survey of psychological distress among Italian people during the COVID19 pandemic: immediate psychological responses and associated factors. International journal of environmental research and public health, 17(9), 1-14. doi: 10.3390/ijerph1 7093165.

MacKay, C., \& DeCicco, T. L. (2020). Pandemic dreaming: The effect of COVID-19 on dream imagery, a pilot study. Dreaming, 30(3), 222-234. doi: 10.1037/drm0000148.

Mota, N. B., Weissheimer, J., Ribeiro, M., de Paiva, M., AvillaSouza, J., Simabucuru, G., Chaves, M.F., Cecchi, L., Cirne, J., Cecchi, G., Rodrigues, C., Copelli, M., Ribeiro, S. (2020). Dreaming during the Covid-19 pandemic: Computational assessment of dream reports reveals mental suffering related to fear of contagion. PLoS One, 15(11), 1-19. doi: 10.1371/journal.pone.0242903.

Musetti, A., Franceschini, C., Pingani, L., Freda, M. F., Saita, E., Vegni, E., Zenesini, C., Quattropani, M., Lenzo, V., Margherita, G., Lemmo, D., Corsano, P., Borghi, L., Cattivelli, R., Plazzi, G., Castelnuovo, G., Somer, E., Schimmenti, A. (2021). Maladaptive daydreaming in an adult Italian population during the COVID-19 lockdown. Frontiers in Psychology, 12, 1-10. doi: 10.3389/fpsyg.2021.631979.

Najam, N., Mansoor, A., Kanwal, R. H., \& Naz, S. (2006). Dream content: Reflections of the emotional and psychological states of earthquake survivors. Dreaming, 16(4), 237245. doi: 10.1037/1053-0797.16.4.237. 
Pesant, N., \& Zadra, A. (2006). Dream content and psychological well-being: A longitudinal study of the continuity hypothesis. Journal of clinical psychology, 62(1), 111-121. doi: 10.1002/jclp.20212.

Pfefferbaum, B., \& North, C. S. (2020). Mental health and the Covid-19 pandemic. New England Journal of Medicine, 383(6), 510-512. doi: 10.1056/NEJMp2008017.

Rajkumar, R. P. (2020). COVID-19 and mental health: A review of the existing literature. Asian journal of psychiatry, 52, 15. doi: 10.1016/j.ajp.2020.102066.

Rossi, R., Socci, V., Talevi, D., Mensi, S., Niolu, C., Pacitti, F., Di Marco, A., Rossi, A., Siracusano, A., \& Di Lorenzo, G. D. (2020). COVID-19 pandemic and lockdown measures impact on mental health among the general population in Italy. Frontiers in Psychology, 11, 1-6. doi: 10.3389/fpsyt. 2020.00790.

Salari, N., Hosseinian-Far, A., Jalali, R., Vaisi-Raygani, A., Rasoulpoor, S., Mohammadi, M., Rasoulpoor, S., \& KhalediPaveh, B. (2020). Prevalence of stress, anxiety, depression among the general population during the COVID-19 pandemic: a systematic review and meta-analysis. Globalization and health, 16(1), 1-11. doi: 10.1186/s12992-020-00589-w.

Scarpelli, S., Alfonsi, V., Mangiaruga, A., Musetti, A., Quattropani, M. C., Lenzo, V., Freda, M., Lemmo, D., Vegni, E., Borghi, L., Saita, E., Cattivelli, R., Castelnuovo, G., Plazzi, G., De Gennaro, L., \& Franceschini, C. (2021). Pandemic nightmares: Effects on dream activity of the COVID-19 lockdown in Italy. Journal of Sleep Research, 1-10. doi: 10.1111 jsr. 13300 .

Schredl, M., \& Bulkeley, K. (2020). Dreaming and the COVID19 pandemic: A survey in a US sample. Dreaming, 30(3), 189-198. doi: 10.1037/drm0000146.

Schredl, M., \& Engelhardt, H. (2001). Dreaming and psychopathology: dream recall and dream content of psychiatric inpatients. Sleep and Hypnosis, 3(1), 44-54.

Sun, N., Wei, L., Wang, H., Wang, X., Gao, M., Hu, X., \& Shi, S. (2021). Qualitative study of the psychological experience of COVID-19 patients during hospitalization. Journal of affective disorders, 278, 15-22. doi: 10.1016/j.jad.2020. 08.040.

Vindegaard, N., \& Benros, M. E. (2020). COVID-19 pandemic and mental health consequences: Systematic review of the current evidence. Brain, behavior, and immunity, 89, 531542. doi: 10.1016/j.bbi.2020.05.048.

Wagnild, G. M., \& Young, H. M. (1993). Development and psychometric. Journal of nursing measurement, 1(2), 165-178. doi: 10.1016/j.tipsro.2017.06.003.

World Health Organization. (2020). Coronavirus disease (COVID-19). Situation report. (March 12nd). Available from: https://www.who.int/docs/default-source/coronaviruse/situation-reports/20200731-covid-19-sitrep193.pdf?sfvrsn=42a0221d 45 